\section{Kidney \\ Blood Pressure Research}

\title{
Fitness for Entering a Simple Exercise Program and Mortality: A Study Corollary to the Exercise Introduction to Enhance Performance in Dialysis (Excite) Trial
}

\author{
Rossella Baggetta ${ }^{a, n} \quad$ Davide Bolignano ${ }^{a, n} \quad$ Claudia Torino ${ }^{a} \quad$ Fabio Manfredini $^{b}$ \\ Filippo Aucellac Antonio Barillàd ${ }^{c}$ Yuri Battagliad ${ }^{d}$ Silvio Bertolie \\ Graziella Bonanno $^{f}$ Pietro Castellinog ${ }^{g}$ Daniele Ciurlino ${ }^{e}$ Adamasco Cupisti $^{h}$ \\ Graziella D'Arrigo ${ }^{a}$ Luciano De Paolai Fabrizio Fabrizij Pasquale Fatuzzo ${ }^{\dagger}$ \\ Giorgio Fuiano' Luigi Lombardi' Gaetano Lucisano' Piergiorgio Messa ${ }^{j}$ \\ Renato Rapanàk Francesco Rapisarda ${ }^{f}$ Stefania Rastellig Lisa Rocca-Rey ${ }^{\mathrm{e}}$ \\ Chiara Summarial Alessandro Zuccalàk Samar Abd ElHafeez ${ }^{m} \quad$ Giovanni Tripepi $^{a}$

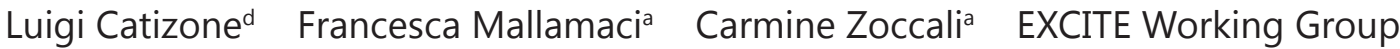

aCNR-IFC, Clinical Epidemiology and Physiopathology of Renal Diseases and Hypertension of Reggio Calabria; bepartment of Biomedical Sciences and Surgical Specialties -Section of Sport Sciences, University of Ferrara; 'Nephrology Unit, Ospedale Casa Sollievo della Sofferenza, San Giovanni Rotondo, Foggia; ${ }^{d}$ Nephrology Unit, AOU Ferrara Arcispedale S. Anna, Ferrara; eNephrology and Dialysis Unit, IRCCS Multimedica - Policlinico Multispecialistico, Sesto S. Giovanni, Milan; ${ }^{f}$ Clinical Division of Chirurgical Nephrology, University of Catania - Azzurra Medical Nephrological Ambulatory and Dialysis Techniques; ${ }^{9}$ Department of Internal Medicine, University of Catania, Catania; ${ }^{h}$ Department of Clinical and Experimental Medicine, University of Pisa; ${ }^{N}$ Nephrology and Dialysis Unit, Ospedale

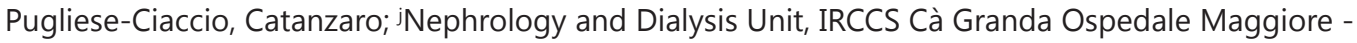
Policlinico, Milano; ${ }^{N}$ Nephrology and Dialysis Unit, Ospedale Civile, Imola; 'Nephrology and Dialysis Unit, Policlinico Universitario Mater Domini, Catanzaro, Italy; mEpidemiology Department, High Institute of Public Health - Alexandria University, Egypt

\section{Key Words}

Physical exercise • Mortality • Outcome study • Dialysis • Deambulation

\begin{abstract}
Background/Aims: In this corollary analysis of the EXCITE study, we looked at possible differences in baseline risk factors and mortality between subjects excluded from the trial because non-eligible $(n=216)$ or because eligible but refusing to participate $(n=116)$.
\end{abstract}

R. Baggetta and D. Bolignano contributed equally to the present work. 


\section{Kidney \\ Blood Pressure Research}

Baggetta/Bolignano/Torino et al.: Deambulation and Study Eligibility in ESRD

Methods: Baseline characteristics and mortality data were recorded. Survival and independent predictors of mortality were assessed by Kaplan-Meier and Cox regression analyses. Results: The incidence rate of mortality was higher in non-eligible vs. eligible non-randomized patients ( 21.0 vs. 10.9 deaths/100 persons-year; $\mathrm{P}<0.001)$. The crude excess risk of death in noneligible patients (HR 1.96; 95\% CI 1.36 to 2.77 ; $\mathrm{P}<0.001$ ) was reduced after adjustment for risk factors which differed in the two cohorts including age, blood pressure, phosphate, CRP, smoking, diabetes, triglycerides, cardiovascular comorbidities and history of neoplasia (HR 1.60; $95 \%$ CI 1.10 to 2.35; P=0.017) and almost nullified after including in the same model also information on deambulation impairment (HR 1.16; $95 \% \mathrm{CI} 0.75$ to $1.80 ; \mathrm{P}=0.513$ ). Conclusions: Deambulation ability mostly explains the difference in survival rate in non-eligible and eligible non-randomized patients in the EXCITE trial. Extending data analyses and outcome reporting also to subjects not taking part in a trial may be helpful to assess the representability of the study population.

Copyright $@ 2014$ S. Karger AG, Basel

\section{Introduction}

Precise definition of the population investigated in clinical trials and in well-planned observational studies is fundamental to understand the potential applicability of findings in these studies in clinical practice. The CONSORT (Consolidated Standards of Reporting Trials) document recommends a specific diagram for describing the flow of participants through the main phases of clinical trials [1], from eligibility to actual enrollment and follow-up. By the same token, a similar approach has been recommended for observational studies by STROBE, another document produced under the aegis of the EQUATOR (Enhancing the QUAlity and Transparency Of health Research) initiative. The importance of accurate reporting of the selection process of subjects enrolled into a trial is of obvious relevance for the generalizability of findings in the same trial. However, outcome data in subjects screened but not enrolled in clinical trials (as not eligible or as refusing to provide consent to participate) have received very little attention and we have been unable to identify even a single study focusing on this issue. The problem appears of particular relevance in trials testing exercise programs, i.e. trials which selects individuals with an inherently lower risk profile, i.e. with a degree of fitness allowing a physical exercise program. We hereby report a study corollary to the EXerCise Introduction To Enhance performance in dialysis (EXCITE) study, i.e. a multicentric, randomized controlled clinical trial on the effectiveness of exercise for improving physical performance and the quality of life and for reducing adverse clinical outcomes (mortality, cardiovascular events and hospitalizations) in dialysis patients (NCT01255969). We specifically designed this study to investigate differences in baseline risk factors and their influence on the overall survival in non-eligible patients and in eligible patients who declined the invitation to participate into the trial.

\section{Patients and Methods}

The study protocol was in conformity to the ethical guidelines of our institution and informed consent was obtained from each participant.

Patients

This is a study corollary to the EXerCise Introduction To Enhance performance in dialysis (EXCITE) study. More detailed information about this trial are available in ClinicalTrials.gov (NCT01255969). In this study we investigated the differences in baseline risk factors and their influence on the incidence rate of mortality in non-eligible patients ( $n=216 ; 90 \%$ on HD) and eligible patients who did not give the informed 


\section{Kidney Blood Pressure Research}

Kidney Blood Press Res 2014;39:197-204

\begin{tabular}{l|l}
\hline DOI: 10.1159/000355797 2014 & $\begin{array}{l}\text { (c 2014 S. Karger AG, Basel } \\
\text { www.karger.com/kbr }\end{array}$ \\
\hline Published online: July 29, 2014 &
\end{tabular}

Baggetta/Bolignano/Torino et al.: Deambulation and Study Eligibility in ESRD

consent to take part into the EXCITE trial $(n=116$; $84 \%$ on HD). Deambulation ability was categorized as independent, assisted or total inability to deambulate (bedridden or wheel-chaired). The main demographic, clinical and biochemical characteristics of patients included in this study are given in Table 1.

\section{Laboratory measurements}

Blood sampling was performed during a midweek day (short dialysis interval). Serum cholesterol, albumin, calcium, phosphate, C-Reactive Protein (CRP) and haemoglobin measurements were made using standard methods in the routine clinical laboratory.

\section{Follow up}

After the initial assessment, the median follow-up was 2.9 years in non-eligible patients (interquartile range 1.2 to 4.0 years) and 4.0 years in eligible patients unwilling to participate into the trial (interquartile range 2.3 to 4.0 years). During follow-up, death was accurately recorded. Each death was reviewed and assigned an underlying cause by a panel of 5 physicians. As a part of the review process, all available medical information about each death were collected. This information always included study and hospitalisation records. In the case of an out-of-hospital death family members were interviewed by telephone to better ascertain the circumstances surrounding death.

\section{Statistical analysis}

Data were expressed as mean \pm standard deviation (normally distributed data), median and interquartile range (non-normally distributed data) or as per cent frequency (categorical data), and the comparisons among groups were made by One Way ANOVA, Kruskal-Wallis Test and Chi Square Test, as appropriate.

In each study cohort, the independent predictors of mortality were identified by Kaplan-Meier survival analysis and by univariate and multivariate Cox regression models. Tested variables included age, gender, smoking, diabetes, blood pressure, total cholesterol, triglycerides, haemoglobin, albumin, calcium, phosphate, C-Reactive Protein, history of neoplasm, myocardial infarction, stroke, TIA, angina episodes, arrhythmia, peripheral vascular disease, and heart failure. We built-up multiple Cox regression models specific to each study cohort, by introducing into these models all variables which were related to all-cause mortality with $\mathrm{P} \leq 0.10$. To assess whether the observed difference in the death risk among the two study cohorts (i.e. non-eligible patients and eligible non-randomized patients) could be explained by differences in baseline risk factors (Table 1), we performed a multiple Cox regression analysis in the whole study population $(n=648)$ including the group (cohort) variable and a series of risk factors which were related

\begin{tabular}{lccc}
\hline & $\begin{array}{c}\text { Non eligible } \\
\mathrm{N}=216\end{array}$ & $\begin{array}{c}\text { Eligible non } \\
\text { randomized } \\
\mathrm{N}=116\end{array}$ & $\mathrm{P}$ \\
\hline Age (years) & $70 \pm 14$ & $67 \pm 14$ & 0.043 \\
Male sex n. (\%) & $119(56)$ & $75(65)$ & 0.111 \\
Smokers n. (\%) & $61(35)$ & $33(49)$ & 0.049 \\
Diabetics n. (\%) & $64(30)$ & $24(21)$ & 0.063 \\
History of neoplasia n. (\%) & $44(21)$ & $29(25)$ & 0.355 \\
Myocardial Infarction n. (\%) & $51(24)$ & $18(16)$ & 0.077 \\
Stroke n. (\%) & $29(14)$ & $11(10)$ & 0.286 \\
Transient Ischemic Attack n. (\%) & $44(21)$ & $11(10)$ & 0.010 \\
Anginal episodes n. (\%) & $35(16)$ & $8(7)$ & 0.015 \\
Arrhythmia n. (\%) & $53(25)$ & $13(11)$ & 0.003 \\
Peripheral vascular disease n. (\%) & $45(21)$ & $4(4)$ & $<0.001$ \\
Heart failure n. (\%) & $145(73)$ & $96(61)$ & 0.02 \\
\hline NYHA class n. (\%): & \multicolumn{3}{c}{} \\
$\quad$ 1 & $54(26)$ & $50(45)$ & $<0.001$ \\
$\quad$ 3-4 & $29(14)$ & $7(6)$ & \\
\hline Deambulation: & $70(34)$ & $10(9)$ & \\
$\quad$ Independent & & & \\
$\quad$ Assisted & $79(37)$ & $107(94)$ & \\
$\quad$ Total inability (bedridden/ wheelchair) & $77(36)$ & $7(6)$ & $<0.001$ \\
\hline Systolic BP (mmHg) & $60(28)$ & $0(0)$ & \\
Diastolic BP (mmHg) & $127 \pm 19$ & $133 \pm 19$ & 0.077 \\
Hypertension n. (\%) & $69 \pm 11$ & $71 \pm 10$ & 0.239 \\
Total cholesterol (mg/dL) & $144(67)$ & $91(78)$ & 0.028 \\
Triglycerides (mg/dL) & $164 \pm 41$ & $171 \pm 50$ & 0.198 \\
Haemoglobin (g/dL) & $153 \pm 73$ & $175 \pm 106$ & 0.05 \\
Albumin (g/dL) & $11 \pm 2$ & $11 \pm 1$ & 0.571 \\
Calcium (mg/dL) & $4.3 \pm 4.8$ & $3.9 \pm 0.4$ & 0.351 \\
Phosphate (mg/dL) & $7.9 \pm 2.0$ & $8.3 \pm 2.0$ & 0.156 \\
CRP (mg/L) & $4.4 \pm 1.4$ & $5.0 \pm 1.8$ & 0.002 \\
\hline Data are expressed as mean \pm SD, median and inter-quartile range or as percent & \\
frequency, as appropriate. & \multicolumn{3}{c}{0.020} \\
\hline
\end{tabular}




\section{Kidney \\ Blood Pressure Research}

Table 2. Univariate Cox regression analyses in the two study cohorts. Categories grading ambulation impairment are listed in Table 1

\begin{tabular}{|c|c|c|c|}
\hline & $\begin{array}{c}\text { Unit of } \\
\text { increase }\end{array}$ & Non eligible patients* & $\begin{array}{c}\text { Eligible non- randomized } \\
\text { patients** }\end{array}$ \\
\hline Age & 1 year & $1.04(1.02-1.06), p<0.001$ & $1.04(1.01-1.06), \mathrm{p}=0.01$ \\
\hline Gender & $0=F ; 1=M$ & $1.17(0.81-1.68), p=0.41$ & $0.90(0.48-1.70), p=0.74$ \\
\hline Smoking & $0=$ no; $1=y e s$ & $1.41(0.95-2.11), p=0.09$ & $1.32(0.60-2.94), p=0.49$ \\
\hline Diabetes & $0=$ no; $1=$ yes & $1.13(0.77-1.66), p=0.54$ & $1.04(0.50-2.19), p=0.91$ \\
\hline Systolic BP & $1 \mathrm{mmHg}$ & $0.99(0.99-1.01), \mathrm{p}=0.47$ & $1.01(0.98-1.03), p=0.56$ \\
\hline Diastolic BP & $1 \mathrm{mmHg}$ & $0.99(0.97-1.00), p=0.11$ & $0.97(0.93-1.01), p=0.12$ \\
\hline Total cholesterol & $1 \mathrm{mg} / \mathrm{dL}$ & $1.00(0.99-1.00), p=0.97$ & $1.00(1.00-1.01), \mathrm{p}=0.35$ \\
\hline Triglycerides & $1 \mathrm{mg} / \mathrm{dL}$ & $0.99(0.99-1.00), p=0.01$ & $1.00(0.99-1.00) p=0.74$ \\
\hline Haemoglobin & $1 \mathrm{~g} / \mathrm{dL}$ & $0.98(0.90-1.06), p=0.58$ & $1.02(0.82-1.27), p=0.87$ \\
\hline Albumin & $1 \mathrm{~g} / \mathrm{dL}$ & $0.99(0.94-1.04), p=0.71$ & $0.93(0.41-2.13), \mathrm{p}=0.86$ \\
\hline Calcium & $1 \mathrm{mg} / \mathrm{dL}$ & $0.99(0.90-1.08), p=0.79$ & $1.02(0.87-1.20), \mathrm{p}=0.84$ \\
\hline Phosphate & $1 \mathrm{mg} / \mathrm{dL}$ & $0.88(0.77-1.00), p=0.05$ & $1.00(0.84-1.20), p=0.99$ \\
\hline CRP & $1 \mathrm{mg} / \mathrm{L}$ & $1.01(1.00-1.01), \mathrm{p}=0.03$ & $0.99(0.94-1.04), p=0.57$ \\
\hline History of myocardial infarction & $0=$ no; $1=y e s$ & $1.25(0.82-1.88), p=0.29$ & $0.50(0.18-1.41), p=0.19$ \\
\hline History of stroke & $0=$ no; $1=$ yes & $1.15(0.68-1.95), p=0.60$ & $1.34(0.52-3.41), p=0.54$ \\
\hline History of TIA & $0=$ no; $1=$ yes & $1.23(0.79-1.89), p=0.36$ & $1.28(0.50-3.26), p=0.61$ \\
\hline History of angina & $0=$ no; 1 =yes & $1.31(0.82-2.07), p=0.26$ & $1.00(0.31-3.23), p=0.99$ \\
\hline History of arrhythmia & $0=$ no; $1=$ yes & $1.39(0.93-2.06), p=0.11$ & $2.24(1.03-4.85), p=0.04$ \\
\hline History of heart failure & $0=$ no; $1=$ yes & $1.46(1.25-1.72), p<0.001$ & $1.05(0.74-1.49), p=0.78$ \\
\hline History of peripheral vascular disease & $0=$ no; $1=$ yes & $1.53(1.00-2.32), p=0.05$ & $1.51(0.37-6.13), p=0.57$ \\
\hline History of neoplasia & $0=$ no; $1=$ yes & $1.37(0.89-2.11), p=0.15$ & $1.98(1.04-3.77), p=0.04$ \\
\hline Deambulation & 1 category & $0.66(0.53-0.83), \mathrm{p}<0.001$ & $0.46(0.17-1.30), \mathrm{p}=0.14$ \\
\hline
\end{tabular}

(with $\mathrm{P} \leq 0.10$ ) to mortality in each study cohort (Table 2) and/or differed (with $\mathrm{P} \leq 0.10$ ) among the two cohorts (Table 1). By this strategy we constructed models of adequate statistical power (i.e. at least 10 deaths for each variable into the models). In the survival analysis, data were expressed as hazard ratio, 95\% confidence interval and $P$ value.

The explained variation in mortality attributable to single variables was calculated by the method proposed by Hosmer and Lemeshow [2]. Statistical analysis was performed by using a standard statistical package (SPSS for Windows, Version 20, Chicago, Illinois, USA.

\section{Results}

The source population of the EXCITE study included 648 patients with ESKD. Among these, 216 patients were excluded because they did not meet inclusion criteria (33\%), 116 patients were eligible but did not give the informed consent $(18 \%)$ and the remaining 316 patients were randomized (49\%). Most non-eligible patients (64\%) did not deambulate autonomously and/or needed to be assisted in everyday life. Eligible patients nonparticipating into the study were significantly younger and displayed a lower proportion of patients with angina, arrhythmia, heart failure and TIA as compared to non-eligible patients. Circulating levels of phosphate and the prevalence of smokers and hypertensive patients were higher in eligible non-randomized patients than in non-eligible patients (Table 1). Circulating levels of C-Reactive Protein (CRP) and the prevalence of peripheral vascular disease were higher in non-eligible patients than in eligible patients who did not give the informed consent (Table 1).

Predictors of mortality in eligible non-randomized patients and in ineligible patients

During the follow-up period, the number of deaths was 119 in non-eligible patients (55\%) and 41 in eligible non-randomized (35\%) patients. In non-eligible patients, age, 


\section{Kidney Blood Pressure Research}

Baggetta/Bolignano/Torino et al.: Deambulation and Study Eligibility in ESRD

Table 3. Separate multiple Cox regression models in non-eligible patients (a) and eligible non- randomized patients (b)

\begin{tabular}{|c|c|c|}
\hline & $\begin{array}{l}\text { Units of } \\
\text { increase }\end{array}$ & HR $(95 \% \mathrm{CI})$ and $\mathrm{P}$ \\
\hline \multicolumn{3}{|c|}{ a) Number of deaths, $n=119$} \\
\hline Age & 1 year & $1.04(1.02-1.06), \mathrm{p}<0.001$ \\
\hline Smoking & $0=$ no; $1=$ yes & $1.13(0.74-1.72), p=0.59$ \\
\hline Triglycerides & $1 \mathrm{mg} / \mathrm{dL}$ & $1.00(0.99-1.00), p=0.04$ \\
\hline Phosphate & $1 \mathrm{mg} / \mathrm{dL}$ & $0.95(0.82-1.10), p=0.95$ \\
\hline CRP & $1 \mathrm{mg} / \mathrm{L}$ & $1.01(1.00-1.02), \mathrm{p}=0.05$ \\
\hline History of peripheral vascular disease & $0=$ no; $1=$ yes & $1.29(0.84-1.99), p=0.25$ \\
\hline Deambulation & 1 unit & $0.72(0.57-0.91), p=0.01$ \\
\hline History of heart failure & $0=$ no; $1=$ yes & $1.81(1.03-3.16), p=0.04$ \\
\hline \multicolumn{3}{|c|}{ b) Number of deaths, $n=41$} \\
\hline Age & 1 year & $1.03(1.00-1.06), p=0.04$ \\
\hline History of arrhythmia & $0=$ no; $1=$ yes & $1.91(0.87-4.17), p=0.11$ \\
\hline History of neoplasia & $0=$ no; $1=$ yes & $1.62(0.84-3.15), p=0.15$ \\
\hline
\end{tabular}

triglycerides, phosphate, CRP, history of heart failure, history of peripheral vascular disease and deambulation degree (autonome, assisted or bedridden/wheelchaired) predicted death with formal statistical significance $(\mathrm{p} \leq 0.05)$ while only age, history of arrhythmia and history of neoplasia associated significantly with the same outcome in eligible patients who did not enter into the trial (Table 2). Non-significant associations ( $p>0.05, p \leq 0.10$ ) with death were noted for smoking (Table 2). In multivariate analyses mortality was predicted only by age, triglycerides, CRP, degree of deambulation and history of heart failure in non-eligible patients (Table 3a) and only by age in eligible non-randomized patients (Table $3 \mathrm{~b}$ ).

\section{Comparison of survival in eligible non-randomized patients and in ineligible patients}

The incidence rate of mortality was substantially higher in non-eligible patients (incidence rate: 21.0 deaths $/ 100$ persons-year) than in eligible non-randomized patients (incidence rate: 10.9 deaths/100 persons-year) (Log rank test: $\chi^{2}=13.85, p<0.001$ ) (Fig. $1 \mathrm{a})$. To assess whether the difference in baseline risk factors could explain the difference in the death risk of the two study cohorts, we performed two multivariate analyses including the group variable of eligible and non-eligible patients (cohorts) and a series of risk factors which were related to mortality (with $\mathrm{p} \leq 0.10$ ) in each study cohort (Table 2 ) and/or differed (with $\mathrm{p} \leq 0.10$ ) among the two cohorts (Table 1). To estimate the impact of the degree of deambulation impairment on mortality we tested two models, the first excluding deambulation ability and the second including this co-variate. In the first model the crude difference in the mortality risk among the two cohorts (HR 1.96; 95\% CI 1.36 to $2.77 ; \mathrm{P}<0.001$ ) was reduced modestly (HR $1.60 ; 95 \%$ CI 1.10 to 2.35 ; $\mathrm{P}=0.017$ ) (Fig.1b and Table 4). However, additional adjustement for deambulation almost nullified the excess risk of death seen in non-eligible patients (HR 1.16; 95\% CI 0.75 to 1.80; P=0.513) (Fig.1c and Table 4). Of note, the explained variation in all-cause mortality was $33 \%$ for the model excluding and $38 \%$ for the model including the deambulation variable $(\mathrm{P}<0.0005)$. Thus, deambulation captures as much as the $13 \%$ in the explained variability in the risk of death.

\section{Discussion}

This study corollary to a multicenter randomized, clinical trial testing the effect of physical exercise in dialysis patients shows that the mortality risk is twice higher in patients who were excluded from the trial than in eligible patients who did not accept to participate. Importantly, the mortality rate in this group (10.9 deaths/100 persons-year) was lower than the average mortality rate in the ERA-EDTA registry [3] and in the Italian registry of dialysis [4]. As expected, the two populations which remained external to the trial, i.e. the 


\section{Kidney

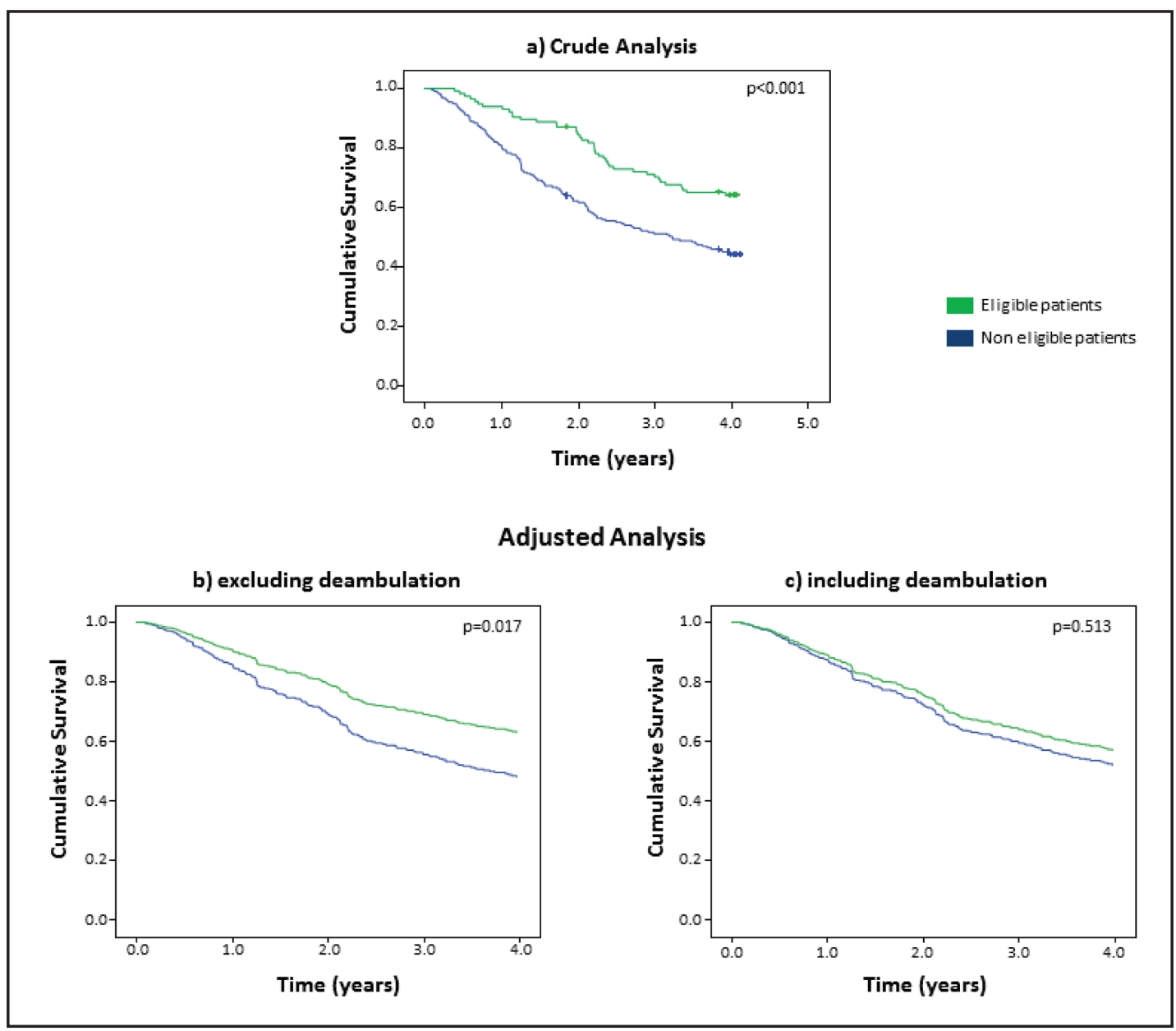

Fig. 1. Unadjusted and adjusted survival analyses in the two study groups (non-eligible and eligible non randomized patients).

ineligible population and the population with sufficient fitness but unwilling to undergo the exercise program, showed several differences in baseline risk factors such as age, blood pressure, phosphate, CRP, smoking, diabetes, triglycerides, cardiovascular comorbidities and history of neoplasia. We hypothesized that these differences could explain the higher death risk of ineligible patients and tested this hypothesis by modeling death risk in an analysis where the two cohorts were nominally identified by a specific covariate. The proviso was that the inclusion of known risk factors differentiating the two cohorts should attenuate substantially or cancel out the excess death risk of unfit patients ineligible to the trial. However, in contrast to our working hypothesis, we found that adjustment for background risk factors only in limited part explained the between cohorts difference in mortality. This finding indicates that major risk factors fail to fully capture the higher probability of death in patients ineligible to clinical studies. Thus, the higher death rate in those patients must necessarily depend on unmeasured risk factors of paramount importance for human health. Most non-eligible patients (64\%) did not deambulate autonomously or needed to be assisted, indicating that comorbidities limiting motor activity in everyday life mark a degree of severity that is unaccounted for by nominally defined, ungraded, major comorbidities like arrhythmia, heart failure, cerebro- and peripheral-vascular disease, ischemic heart disease and neoplasia. Indeed, when we introduced into the model deambulation impairment, the between cohorts difference in the risk of death almost disappeared (HR 1.16; 95\% CI 0.75 


\section{Kidney \\ Blood Pressure Research}

Table 4. Multivariate Cox regression analysis in the whole study population

\begin{tabular}{|c|c|c|c|c|}
\hline & \multirow[b]{2}{*}{$\begin{array}{l}\text { Units of } \\
\text { increase }\end{array}$} & \multirow[b]{2}{*}{ Crude analysis** } & \multicolumn{2}{|c|}{ Adjusted analysis } \\
\hline & & & $\begin{array}{c}\text { Excluding } \\
\text { Deambulation** }\end{array}$ & $\begin{array}{c}\text { Including } \\
\text { Deambulation** }\end{array}$ \\
\hline Eligible non-randomized patients & 1 & $1^{*}$ & $1^{*}$ & $1^{*}$ \\
\hline Non eligible patients & 2 & $\begin{array}{c}1.94(1.36-2.77) \\
\mathrm{p}<0.001\end{array}$ & $\begin{array}{c}1.60(1.10-2.35) \\
\mathrm{p}=0.017\end{array}$ & $\begin{array}{c}1.16(0.75-1.80) \\
p=0.513\end{array}$ \\
\hline Age & 1 year & & $\begin{array}{c}1.03(1.02-1.05) \\
\mathrm{p}<0.001\end{array}$ & $\begin{array}{c}1.03(1.02-1.05) \\
\mathrm{p}<0.001\end{array}$ \\
\hline Systolic BP & $1 \mathrm{mmHg}$ & & $\begin{array}{c}1.00(1.00-1.01) \\
\mathrm{p}=0.86\end{array}$ & $\begin{array}{c}1.00(1.00-1.01) \\
p=0.77\end{array}$ \\
\hline Triglycerides & $1 \mathrm{mg} / \mathrm{dL}$ & & $\begin{array}{c}1.00(1.00-1.00) \\
\mathrm{p}=0.13\end{array}$ & $\begin{array}{c}1.00(1.00-1.00) \\
\mathrm{p}=0.27\end{array}$ \\
\hline Phosphate & $1 \mathrm{mg} / \mathrm{dL}$ & & $\begin{array}{c}0.96(0.85-1.08) \\
p=0.49\end{array}$ & $\begin{array}{c}0.99(0.88-1.11) \\
p=0.85\end{array}$ \\
\hline CRP & $1 \mathrm{mg} / \mathrm{L}$ & & $\begin{array}{c}1.01(1.00-1.02) \\
\mathrm{p}=0.08\end{array}$ & $\begin{array}{c}1.01(1.00-1.01) \\
p=0.14\end{array}$ \\
\hline Smoking & $0=$ no; $1=$ yes & & $\begin{array}{c}1.26(0.87-1.83) \\
\mathrm{p}=0.21\end{array}$ & $\begin{array}{c}1.27(0.88-1.85) \\
p=0.21\end{array}$ \\
\hline Diabetes & $0=$ no; $1=$ yes & & $\begin{array}{c}1.10(0.75-1.60) \\
p=0.64\end{array}$ & $\begin{array}{c}0.92(0.92-1.37) \\
p=0.69\end{array}$ \\
\hline History of myocardial infarction & $0=$ no; $1=$ yes & & $\begin{array}{c}0.87(0.57-1.34) \\
p=0.53\end{array}$ & $\begin{array}{c}0.87(0.57-1.33) \\
p=0.52\end{array}$ \\
\hline History of TIA & $0=$ no; $1=$ yes & & $\begin{array}{c}1.07 \begin{array}{c}(0.71-1.62) \\
p=0.75\end{array}\end{array}$ & $\begin{array}{c}0.96(0.63-1.47) \\
p=0.86\end{array}$ \\
\hline History of angina & $0=$ no; $1=$ yes & & $\begin{array}{c}0.97(0.59-1.58) \\
p=0.90\end{array}$ & $\begin{array}{c}1.03(0.63-1.67) \\
p=0.92\end{array}$ \\
\hline History of arrhythmia & $0=$ no; $1=$ yes & & $\begin{array}{c}1.17 \begin{array}{c}(0.81-1.70) \\
\mathrm{p}=0.40\end{array}\end{array}$ & $\begin{array}{c}1.20(0.83-1.74) \\
\mathrm{p}=0.34\end{array}$ \\
\hline History of peripheral vascular disease & $0=$ no; $1=$ yes & & $\begin{array}{c}1.41(0.92-2.16) \\
p=0.12\end{array}$ & $\begin{array}{c}1.38(0.90-2.13) \\
p=0.14\end{array}$ \\
\hline History of heart failure & $0=$ no; $1=$ yes & & $\begin{array}{c}1.46(0.96-2.21) \\
\mathrm{p}=0.08\end{array}$ & $\begin{array}{c}1.34(0.88-2.04) \\
p=0.18\end{array}$ \\
\hline Hypertension & $0=$ no; $1=$ yes & & $\begin{array}{c}0.99(0.67-1.46) \\
p=0.97\end{array}$ & $\begin{array}{c}1.04(0.71-1.54) \\
p=0.84\end{array}$ \\
\hline History of neoplasm & $0=$ no; $1=$ yes & & $\begin{array}{c}1.26(0.86-1.84) \\
p=0.24\end{array}$ & $\begin{array}{c}1.29(0.88-1.90) \\
p=0.19\end{array}$ \\
\hline Deambulation & 1 category & & & $\begin{array}{c}0.66(0.52-0.84) \\
p=0.001\end{array}$ \\
\hline
\end{tabular}

to 1.80; $\mathrm{P}=0.513$ ). This observation is of importance because physical performance and inability to deambulate are very rarely taken into account when describing the risk profile of dialysis patients in major clinical trials and observational studies in this population. For example, neither in the 4D [5], nor in the AURORA study [6], nor in the more recent EVOLVE trial [7], physical disability was an exclusion criterion but in none of these trials information on physical disability was given. About $1 / 3(33 \%)$ of the source cohort of the EXCITE study had a relevant degree of physical impairment and it is likely that a similar proportion existed in the source populations of other trials in dialysis patients. The variability in mortality rate explained by unfitness to a simple exercise program is substantial and ignoring severe limitation in physical functioning may have a non trivial effect for the interpretation of the risk profile of patients included in clinical studies. However, as discussed, information on ambulatory ability is almost always omitted in trials in the dialysis population. Findings in this study represent a call for systematic reporting information on physical activity and/or (motor) ability in clinical trials and observational studies in this population. Indeed -well beyond classical risk factors, background co-morbidities and risk factors peculiar to end-stage renal disease- deambulation impairment explains a relevant proportion of the variability in mortality in ESKD. Furthermore, our findings suggest that extending outcome reporting and data analyses to the whole source population of clinical trials may provide relevant information to better frame the implications of the selection process applied to restrict the trial population to patients with well-defined demographic and clinical characteristics. 


\section{Kidney \\ Blood Pressure Research}

Disclosure Statement
Kidney Blood Press Res 2014;39:197-204

\begin{tabular}{l|l}
\hline DOI: $10.1159 / 000355797$ & (c) 2014 S. Karger AG, Basel
\end{tabular}

Published online: July 29, 2014

www.karger.com/kbr

Baggetta/Bolignano/Torino et al.: Deambulation and Study Eligibility in ESRD

The authors of this manuscript state that they do not have any conflict of interests and nothing to disclose.

\section{References}

1 Bolignano D, Mattace-Raso F, Torino C, D’Arrigo G, Abd ElHafeez S, Provenzano F, Zoccali C, Tripepi G: The quality of reporting in clinical research: the CONSORT and STROBE initiatives. Aging Clin Exp Res 2013;25:9-15.

2 Hosmer DW, Lemeshow S, May S: Applied survival analysis Assessment of Model Adequacy, in Applied Survival Analysis: Regression Modeling of Time-to-Event Data, Second Edition, John Wiley \& Sons, Inc., Hoboken, NJ, USA. doi: 10.1002/9780470258019.ch6 New York, USA, 2008, pp 196-240.

3 ERA-EDTA. ERA-EDTA registry Annual Report 2011 [cited 2014 04/04]. Available from: http://www.eraedta-reg.org/files/annualreports/pdf/AnnRep2011.pdf, 2014.

4 Nefrologia SId. Registro Italiano di Dialisi e Trapianto 2010 [cited 2014 04/04]. Available from: http:// www.sin-ridt.org/web/eventi/RIDT/index.cfm, 2014.

-5 Wanner C, Krane V, März W, Olschewski M, Mann JF, Ruf G, Ritz E; German Diabetes and Dialysis Study Investigators: Atorvastatin in patients with type 2 diabetes mellitus undergoing hemodialysis. N Engl J Med 2005;353:238-248.

-6 Schneider A, Jardine AG, Schneider MP, Holdaas H, Holme I, Fellstroem BC, Zannad F, Schmieder RE; AURORA Study Group: Determinants of cardiovascular risk in haemodialysis patients: post hoc analyses of the AURORA study. Am J Nephrol 2013;37:144-151.

7 EVOLVE Trial Investigators, Chertow GM, Block GA, Correa-Rotter R, Drüeke TB, Floege J, Goodman WG, Herzog CA, Kubo Y, London GM, Mahaffey KW, Mix TC, Moe SM, Trotman ML, Wheeler DC, Parfrey PS: Effect of cinacalcet on cardiovascular disease in patients undergoing dialysis. N Engl J Med 2012;367:2482-2494. 